\title{
Red pitanga chewable candies: physicochemical, microbiological, and sensory characterization
}

\author{
Lisiane PINTANELA VERGARA ${ }^{1}$ (D), Gabriela NIEMEYER REISSIG ${ }^{2}$ (D), Rui Carlos ZAMBIAZI ${ }^{3}$ (D), \\ Rosane DA SILVA RODRIGUES ${ }^{3}$ (D) , Josiane FREITAS CHIM ${ }^{3}$ (D)
}

\begin{abstract}
The use of red pitanga pulp in the manufacture of candies is an alternative to the use of artificial colors and flavorings. This study aimed to evaluate the content of potentially bioactive compounds, microbiological quality, and sensory characteristics of conventional and low-calorie chewable candies formulated with red pitanga pulp and stored for 180 days under environmental conditions. Physicochemical, microbiological, and sensory analyses were performed. The storage of these products for 180 days influenced the contents of phenolic compounds and monomeric anthocyanins. Antioxidant activity was null at the end of the storage period. Conventional candy had the highest content of bioactive compounds. Contamination by thermotolerant coliforms and Salmonella spp. was not observed. Sensory evaluation showed an acceptability index greater than $70 \%$, indicating that the products in this study have good potential for consumption and insertion in the market.
\end{abstract}

Keywords: bioactive compounds; comfit; Eugenia uniflora L.; native fruit; Surinam cherry.

Practical Application: Add value to candies and market diversification.

\section{Introduction}

In general, candies are prepared by cooking sugars and adding food coloring, flavoring, and acidulants. They may also contain other substances allowed by the Brazilian legislation, which are characteristic for each type of candy. Chewable candy differs from hard candy, and its formulation employs fat, lower cooking temperatures, and higher percentages of moisture (Vissoto \& Luccas, 1999). Brazil is the third-largest producer of candies and confectioneries after the United States and Germany (Associação Brasileira da Indústria de Chocolates Amendoim e Balas, 2019).

There are few studies related to the insertion of fruit pulps, especially native fruits, in the formulation of chewable candies. Native fruits have potentially bioactive compounds, such as phenolic and carotenoid compounds, which contribute to their antioxidant capacity and color. Vergara et al. (2020a) studied the effect of the retention of bioactive compounds in chewable candies formulated with blended pulp containing the pulps of blackberry, butiá, and red pitanga. In relation to the amount of pulp used in the formulation of the candies, $72.38 \%$ of phenolic compounds and $67.36 \%$ of carotenoids were retained. The incorporation of fruit pulps in confectionery is an innovative option for the production of chewable candies, as they are natural ingredients that can improve the sensory quality (flavor, color, and aroma) and characteristics (fiber, vitamin, mineral, and bioactive compound contents) of the final product (Mongia, 2014).
In addition, there is currently a trend in the consumption of less caloric, more nutritious, and therefore, healthier foods. Light products meet this demand and are constantly undergoing technological innovations and expanding their market offers. Hence, the processing of low-calorie chewable candies, whose appeal adds to the current market trend, differs from the conventional process, and may result in changes in the physical, chemical, and sensory characteristics of the product (Reissig et al., 2016).

Among native fruits, the fruit of the pitanga tree (Eugenia uniflora $\mathrm{L}$.), originally from the region that extends from central Brazil to northern Argentina, stands out for its easy adaptation to the most different conditions of climate and soil, which allows its cultivation in other regions of Brazil and the world. Pitanga is a fruit rich in vitamins, mainly precursors of vitamin $\mathrm{A}$, and potentially bioactive compounds, such as phenolic and carotenoid compounds, which contribute to its antioxidant capacity (Franzon, 2013; Lira et al., 2007; Moura et al., 2011). Studies have shown that pitanga exhibits great inhibitory potential for the enzyme alpha-glycosidase, indicating its applicability in the control of type 2 diabetes (Franzon, 2013; Lira et al., 2007; Moura et al., 2011; Vinholes et al., 2017). In addition, the use of pitanga as an alternative to food coloring and artificial flavoring opens up the possibility of using endemic small fruits from Brazil's southern region. Therefore, the objective of this work was to evaluate some physicochemical attributes, mainly the content of potentially bioactive compounds, the microbiological quality, 
and the sensory acceptability of conventional and low-calorie chewable candies formulated with red pitanga pulp and packaged for 180 days under environmental conditions.

\section{Materials and methods}

\subsection{Plant material and production of chewable candies}

The red pitanga fruit used in this work was transferred from a crop at Embrapa Clima Temperado-Pelotas/RS (geographical coordinates: $31^{\circ} 40^{\prime} 47^{\prime \prime} \mathrm{S}$ and $52^{\circ} 26^{\prime} 24^{\prime \prime} \mathrm{W}$ : $60 \mathrm{~m}$ altitude), harvested at commercial maturity point (uniform red color of the peel) and stored at $-80{ }^{\circ} \mathrm{C}$ until the experiment was conducted. The fruits were selected, washed, sanitized in a 200 ppm chlorinated solution, and pulped in a horizontal pulping machine (2 $\mathrm{mm}$ mesh). Two formulations of chewable candies with pitanga pulp were developed: conventional and low-calorie. The main difference between the formulations is the presence of sweeteners in the low-calorie candy formulation, with the respective reduction in the amount of sugar; however, the contents of the other components were also slightly adjusted to obtain products with similar sweetness and texture characteristics. For conventional chewable candy preparation, the following were used: $7.2 \%$ pitanga pulp, $18.30 \%$ potable water, $36.01 \%$ crystal sugar, $33.01 \%$ glucose syrup (dextrose equivalent: $38-40 \%$ ), $4.91 \%$ vegetable fat, $0.33 \%$ emulsifier, $0.029 \%$ sodium chloride, $0.18 \%$ unflavored gelatin, and $0.033 \%$ citric acid. For low-calorie chewable candy preparation, the following were used: $6.43 \%$ pitanga pulp, $16.34 \%$ potable water, $10.72 \%$ refined sugar, $16.07 \%$ light sugar, $16.07 \%$ sorbitol (70\%), $29.47 \%$ glucose syrup (dextrose equivalent: $38-40 \%$ ), $4.38 \%$ vegetable fat, $0.29 \%$ emulsifier, $0.026 \%$ sodium chloride, $0.16 \%$ flavorless gelatin, and $0.029 \%$ citric acid. All the ingredients were purchased locally. The pulp concentrations were chosen based on previous experiments in order to achieve the suitable color and consistency for the low-calorie formulation, which led to a $0.7 \%$ pulp reduction. Chewable candies were prepared according to the flowchart proposed by Fadini et al. (2003), with a few modifications, in a stainless steel container at atmospheric pressure and under constant manual agitation with a final process temperature of $123{ }^{\circ} \mathrm{C}$. The processing times of conventional and low-calorie candies averaged 8 and $10 \mathrm{~min}$, respectively. After molding (Figure 1), the candies were individually wrapped in bioriented polypropylene packaging and stored in a room with air conditioning temperature $\left(20-22^{\circ} \mathrm{C}\right)$ for $180 \mathrm{~d}$. The candies were analyzed in triplicate, starting the day after processing and at different storage periods $(60,120$ and $180 \mathrm{~d}$, respectively).

\subsection{Color attributes}

The color was evaluated based on the CIELAB system, using a Minolta colorimeter (Minolta Chromometer CR 300) with the D65 illuminant and calibrated with a white porcelain plate (Mahawar et al., 2018). The color parameters were used to calculate the hue angle $\left({ }^{\circ}\right.$ Hue $\left.=\tan -1 b^{*} / a^{*}\right)$.

\subsection{Phenolic compound content}

Phenolic compounds were determined spectrophotometrically using the methodology proposed by Singleton \& Rossi (1965). The absorbance was read at $725 \mathrm{~nm}$ (Jenway 6700, Jenway, Spain). Quantification was based on the establishment of a standard curve, which yielded a straight-line equation: $\mathrm{y}=0.0046 \mathrm{x}+$ $0.0004 \mu \mathrm{g} / \mathrm{mL}$. The results were expressed in mg equivalents of gallic acid in $100 \mathrm{~g}$ of fresh weight $(\mathrm{FW})$.

\subsection{Monomeric anthocyanin content}

Monomeric anthocyanin content was quantified using the methodology proposed by Rodriguez-Saona \& Wrolstad (2001). For extraction, the method described by Lees \& Francis (1972) was used. The absorbance was read on a spectrophotometer (Jenway $6700 \mathrm{UV}$-Vis, Jenway, Spain) at $520 \mathrm{~nm}$. The anthocyanin concentration was calculated using the differential $\mathrm{pH}$ (Equation 1 and Equation 2). The results were expressed in $\mathrm{mg}$ of cyanidine3-glycoside per $100 \mathrm{~g}$ FW.

$A=(A 520-A 700) p H 1.0-(A 520-A 700) p H 4.5$

Monomeric anthocyanins $\left(\operatorname{mg} .100 g^{-1}\right)=A x P M \times F D \times 100(\varepsilon \times 1)$

where $\mathrm{A}$ is the absorbance (Equation 1), MW is the molecular weight of cyanidine-3-glycoside (449.2), DF is the dilution factor, and $\varepsilon$ is the molar absorption coefficient of cyanidine3-glycoside $\left(26.900 \mathrm{M}^{-1} \mathrm{~cm}^{-1}\right)$.

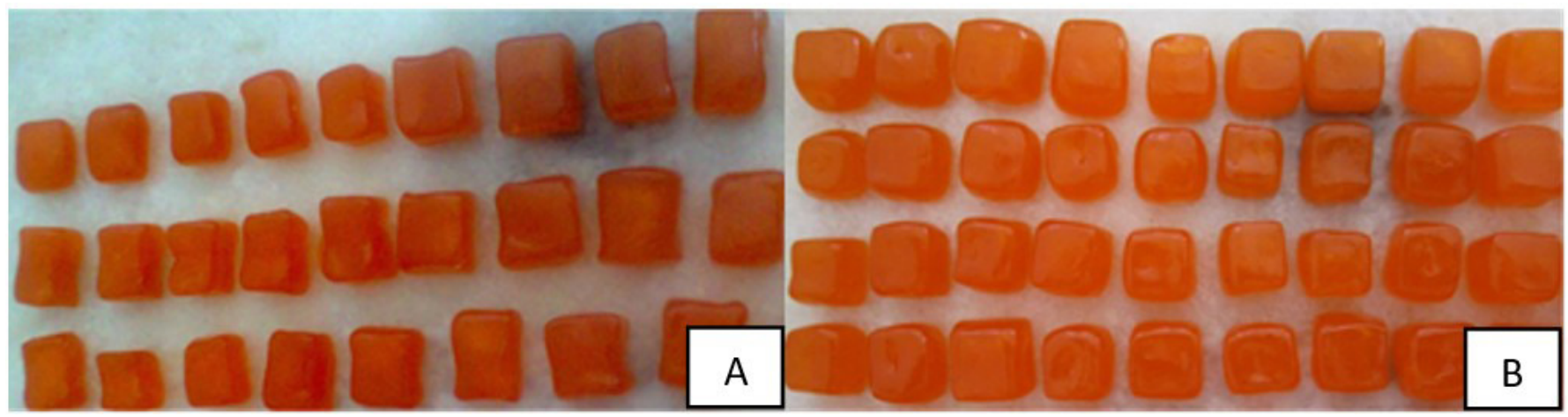

Figure 1. Conventional (A) and low-calorie (B) red pitanga chewable candies. 


\subsection{Total carotenoid content}

The total carotenoid content was quantified using Association of Official Analytical Chemists (2005) method 970.64. The absorbance of the supernatant was read on a spectrophotometer (Jenway $6700 \mathrm{UV}$-Vis) at $450 \mathrm{~nm}$. The results were expressed in $\mathrm{mg}$ of $\beta$-carotene in $100 \mathrm{~g}$ FW.

\subsection{Radical-scavenging activity}

To determine the total antioxidant capacity, two different methods were used: the DPPH and ABTS radical methods. The capture of the $\mathrm{DPPH}^{\circ}$ radical (2,2-diphenyl-1-picryl-hydrazil) was determined using the method of Brand-Williams et al. (1995). The absorbance was measured at $517 \mathrm{~nm}$ using a spectrophotometer (Jenway $6700 \mathrm{UV}-\mathrm{Vis}$ ). The capture of the $\mathrm{ABTS}^{\circ}$ radical (2,2-azino-bis-3-ethylbenzthiazoline-6-sulfonic acid) was determined using the method of Rufino et al. (2007). The absorbance was measured on a spectrophotometer at $734 \mathrm{~nm}$ (Jenway $6700 \mathrm{UV}-\mathrm{Vis}$ ) after $6 \mathrm{~min}$ of reaction. The results were expressed as percentage (\%) of inhibition of DPPH and ABTS radicals, using Equação 3.

$\%$ of inhibition $=100-\frac{(\text { Acontrol }- \text { Asample }) \times 100}{\text { Acontrol }}$

where $\mathrm{A}$ is the sample absorption.

\subsection{Microbiological quality assessment}

Salmonella spp. analysis and thermotolerant coliforms count (TCC) determination for conventional and low-calorie candies were performed using the most probable number (MPN) technique, immediately after processing. The microbiological standard adopted was established by Resolution RDC No. 12/2001 of the National Health Surveillance Agency (Agência Nacional de Vigilância Sanitária - ANVISA). After the analysis and verification of the results, interpretation was carried out in accordance with Resolution No. 12/2001 (Brasil, 2001). For TCC analysis, the method described by Silva et al. (2007) was used.

\subsection{Sensory evaluation}

Sensory evaluation was carried out at the Municipal School of Elementary Education (Margarida Gastal - Campus Universitário, Capão do Leão-RS). It was performed after obtaining the results of the microbiological analysis, which certified the food as safe for consumption. Children were chosen as tasters because they are regular consumers of candies, and also to evaluate the possibility of introducing native fruits into their diet. The candies were evaluated using an affective method, the acceptance test, in which 70 children of both sexes ( $50 \%$ boys and $50 \%$ girls), aged between 5 and 10 years, participated. A candy unit $( \pm 2.0 \mathrm{~g})$ was served to the tasters in a monadic manner on alternate days, so as to not cause fatigue. The test was carried out by means of an evaluation form containing a hedonic facial scale ranging from 1 to 7 , which anchored axis 1 to "excellent" and axis 7 to "horrible." The acceptability index (AI) for the candies was calculated using the relationship between the average score obtained for the product and the maximum score given to the product, and expressed as a percentage (Associação Brasileira de Normas
Técnicas, 1993; Queiroz \& Treptow, 2006). The application of the sensory test was approved by the Ethics Committee of the Faculty of Medicine at the Federal University of Pelotas, with the project registered at Plataforma Brasil (opinion number: 901.768).

\subsection{Statistical analysis}

Treatments and physicochemical analyses were performed in triplicate. The data were expressed as means \pm standard deviations. The physicochemical analysis data were subjected to analysis of variance (ANOVA) and, in the case of significant difference, comparison of means by the t-test $(\mathrm{p} \leq 0.05)$. The $95 \%$ confidence interval was calculated for comparison among storage periods within each candy formulation.

\section{Results and discussion}

\subsection{Color attributes}

It was hypothesized that red pitanga fruit is a natural and innovative option that has potential to be used as an ingredient in the confectionery industry for the production of chewable candies with both nutritional and sensory appeal. For such, the pitanga must be stable to processing and storage. Regarding the color attributes, the storage period induced a significant difference $(\mathrm{p} \leq 0.05)$ between the parameters evaluated for the chromatic evaluation of the products (Figure 2). After 1 and 60 days of storage, the candies showed a significant difference $(\mathrm{p} \leq 0.05)$ in luminosity, with the conventional chewable candy having a luminosity close to 100 and appearing brighter than the low-calorie one (Table 1). After this storage period, both types of candies were darker. The type of packaging used in the present study (transparent bioriented polypropylene) probably influenced the reduction in luminosity, owing to photo-oxidation reactions. The packaging for candies must be selected to provide a light barrier, ensuring the maintenance of product quality for a longer period (Centro de Tecnologia de Embalagem, 1993).

The freshly processed candies differed significantly $(\mathrm{p} \leq 0.05)$ in color tone ( $\left.{ }^{\circ} \mathrm{Hue}\right)$, with the low-calorie candy showing a greater intensity of red color (Figure 2). Despite the higher percentage of pulp in the conventional formulation, the lowcalorie candy had a more reddish color tone. The most likely explanation for the phenomenon is the longer processing time and possible caramelization effect. During the caramelization process, by heating the sugar to temperatures generally above $120^{\circ} \mathrm{C}$, dehydration occurs and the generation of double bonds with the formation of rings and labile compounds, which condense and form polymers responsible for the caramel color and aroma (Zhang et al., 2013). Interestingly, after 60 days of storage, there is an increase in the hue angle, and a consequent decrease in the reddish hue. Comparing with the pigment data (Figure 3), there is no apparent decrease to justify the observed phenomenon. We can assume that some degradation of dark compounds formed during processing may have occurred. When 1 and 60 days of storage were compared, the candies showed a significant difference $(\mathrm{p} \leq 0.05)$ in color tone. The low-calorie candy showed an increase in color tone during the storage period, between $0^{\circ}$ and $90^{\circ}$, that is, from reddish orange to 
orange color. After 120 and 180 days of storage, the candies showed no significant difference $(\mathrm{p} \leq 0.05)$ in luminosity and color tone ( $\left.{ }^{\circ} \mathrm{Hue}\right)$.

\subsection{Phenolic compound, monomeric anthocyanin, and total carotenoid contents}

The pitanga candies showed a significant difference $(\mathrm{p} \leq 0.05)$ in phenolic compound content over the storage period; although

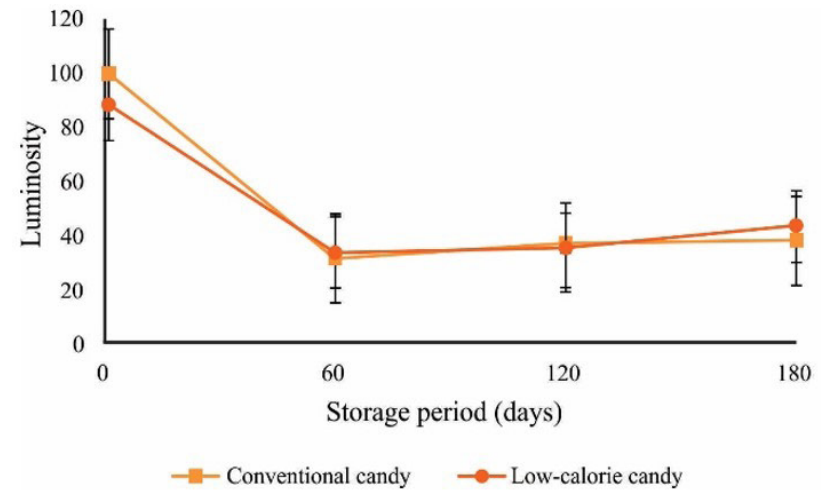

the values fluctuated, there was a significant increase in the content of phenolic compounds at the end of the storage period (Figure 3 ). These results were probably a consequence of the hydrolysis of conjugated polyphenols from the pitanga pulp during candy production (Silva et al., 2016). Some researchers have reported that processing affects the content of phenolic compounds and can result in the loss or enrichment of some polyphenols (Haminiuk et al., 2012; Vergara et al., 2020b). The candies prepared

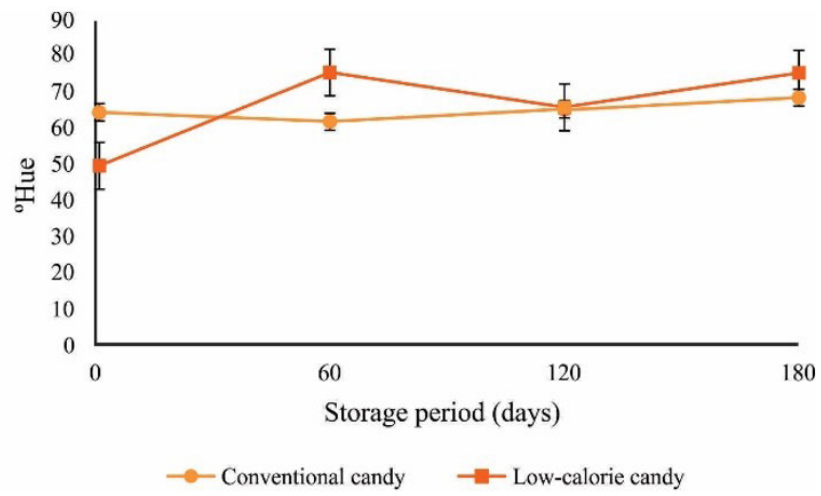

Figure 2. Luminosity and hue angle ( $\left.{ }^{\circ} \mathrm{Hue}\right)$ of conventional and low-calorie red pitanga chewable candies during 180 days of storage. The points in the lines represent de mean and the vertical bars indicate the $95 \%$ confidence interval among storage periods within each candy formulation.

Table 1. Physical and phytochemical characteristics of conventional and low-calorie red pitanga (Eugenia uniflora L.) chewable candies during 180 days of storage.

\begin{tabular}{|c|c|c|c|}
\hline Analysis & Storage period (days) & Conventional candy & Low-calorie candy \\
\hline \multirow[t]{4}{*}{ Luminosity } & 1 & $99.66 \pm 1.01 \mathrm{a}$ & $88.31 \pm 0.75 b$ \\
\hline & 60 & $31.64 \pm 1.24 \mathrm{~b}$ & $33.88 \pm 0.60 \mathrm{a}$ \\
\hline & 120 & $37.26 \pm 2.74 \mathrm{a}$ & $35.53 \pm 1.37 \mathrm{a}$ \\
\hline & 180 & $38.52 \pm 1.80 \mathrm{a}$ & $43.81 \pm 2.95 a$ \\
\hline \multirow[t]{4}{*}{${ }^{\circ}$ Hue } & 1 & $64.26 \pm 2.98 \mathrm{a}$ & $49.49 \pm 5.93 b$ \\
\hline & 60 & $61.65 \pm 2.45 b$ & $75.31 \pm 1.65 a$ \\
\hline & 120 & $65.14 \pm 3.99 \mathrm{a}$ & $65.60 \pm 1.27 \mathrm{a}$ \\
\hline & 180 & $68.33 \pm 5.79 \mathrm{a}$ & $75.03 \pm 4.04 \mathrm{a}$ \\
\hline \multirow{4}{*}{ Total phenols ${ }^{1}$} & 1 & $16.23 \pm 0.50 \mathrm{a}$ & $16.54 \pm 0.12 \mathrm{a}$ \\
\hline & 60 & $11.86 \pm 0.25 \mathrm{a}$ & $9.75 \pm 0.83 b$ \\
\hline & 120 & $12.00 \pm 1.46 \mathrm{a}$ & $12.41 \pm 0.24 \mathrm{a}$ \\
\hline & 180 & $26.93 \pm 1.81 \mathrm{a}$ & $20.24 \pm 2.33 b$ \\
\hline \multirow[t]{4}{*}{ Monomeric anthocyanins ${ }^{2}$} & 1 & $43.58 \pm 1.52 \mathrm{a}$ & $44.25 \pm 1.13 \mathrm{a}$ \\
\hline & 60 & $3.38 \pm 2.35 \mathrm{a}$ & $7.56 \pm 3.58 \mathrm{a}$ \\
\hline & 120 & $10.81 \pm 1.49 \mathrm{a}$ & $1.17 \pm 0.59 b$ \\
\hline & 180 & $17.53 \pm 6.35 \mathrm{a}$ & $6.64 \pm 2.38 b$ \\
\hline \multirow[t]{4}{*}{ Total carotenoids ${ }^{3}$} & 1 & $5.45 \pm 1.96 \mathrm{a}$ & $2.81 \pm 1.11 \mathrm{a}$ \\
\hline & 60 & $5.78 \pm 0.03 a$ & $5.76 \pm 0.56 \mathrm{a}$ \\
\hline & 120 & $3.92 \pm 1.01 \mathrm{a}$ & $4.04 \pm 0.80 \mathrm{a}$ \\
\hline & 180 & $3.55 \pm 0.80 \mathrm{a}$ & $3.39 \pm 0.18 \mathrm{a}$ \\
\hline \multirow[t]{4}{*}{$\mathrm{DPPH}^{\circ} 4$} & 1 & $1.85 \pm 0.71 \mathrm{a}$ & $2.93 \pm 1.22 \mathrm{a}$ \\
\hline & 60 & $1.37 \pm 0.41 \mathrm{a}$ & $1.52 \pm 0.00 \mathrm{a}$ \\
\hline & 120 & $0.00 \pm 0.00$ & $0.00 \pm 0.00$ \\
\hline & 180 & $0.00 \pm 0.00$ & $0.00 \pm 0.00$ \\
\hline \multirow[t]{4}{*}{$\mathrm{ABTS}^{*}$} & 1 & $4.90 \pm 0.67 \mathrm{a}$ & $6.50 \pm 1.22 \mathrm{a}$ \\
\hline & 60 & $8.62 \pm 2.03 a$ & $5.56 \pm 0.00 \mathrm{a}$ \\
\hline & 120 & $0.00 \pm 0.00$ & $0.00 \pm 0.00$ \\
\hline & 180 & $0.00 \pm 0.00$ & $0.00 \pm 0.00$ \\
\hline
\end{tabular}

Values are expressed as mean \pm SD. The same lowercase letters on the line indicate that the treatments did not differ according to the $\mathrm{t}$-test (p $\leq 0.05) .{ }^{1} \mathrm{mg}$ gallic acid in $100 \mathrm{~g}$ FW. ${ }^{2} \mathrm{mg}$ cyanidine-3-glycoside in $100 \mathrm{~g}$ FW. ${ }^{3} \mathrm{mg} \beta$-carotene in $100 \mathrm{~g} \mathrm{FW.}{ }^{4} \%$ radical inhibition in FW. 
in the present study did not show significant differences $(\mathrm{p} \geq 0.05)$ in phenolic compound content after 1 and 120 days of storage (Table 1). After 60 and 180 days of storage, the conventional candies showed a significantly $(\mathrm{p} \leq 0.05)$ higher concentration of phenolic compounds than the low-calorie candies. Despite the lower percentage of pulp in the low-calorie formulation, there was no significant difference $(\mathrm{p} \geq 0.05)$ between the candies until the last storage period. The content of phenolic compounds is highly dependent on the type of food and the processing conditions (Rickman et al., 2007). A possible explanation for the content of phenolic compounds in low-calorie candy is that the temperature and longer processing time concentrated the compounds or made them more available (Cruxen et al., 2017). At the end of the storage period, the higher moisture content in low-calorie candies may have facilitated the syneresis process and exposure of phenolic compounds to oxidative agents, reflecting their lower content at 180 days of storage (Figure 3 ). Vergara et al. (2020b) quantified the content of phenolic compounds in chewable candies formulated with blended pulp (blackberry, butiá, and pitanga). They reported values of $23.46 \pm 2.06 \mathrm{mg}$ of gallic acid $100 \mathrm{~g}^{-1}$, which are lower than those found in the present study, right after the processing of the candies. These differences can be explained by the physicochemical characteristics of each fruit pulp used and the differences in the processing parameters.

There was a significant difference $(\mathrm{p} \leq 0.05)$ in the contents of monomeric anthocyanins throughout the storage period in both the candies (Figure 3 ). The candies did not differ significantly $(\mathrm{p} \geq 0.05)$ in monomeric anthocyanin content after 1 and 60 days of storage (Table 1). After 120 and 180 days of storage, the conventional candy showed a significantly higher $(\mathrm{p} \leq 0.05)$ content of monomeric anthocyanins compared with the lowcalorie formulation. However, after 180 days, the anthocyanin contents in the conventional and low-calorie candies decreased by $59.78 \%$ and $85 \%$, respectively. Anthocyanins are soluble pigments that are highly unstable at high temperatures, light and oxygen exposure. These conditions are present during the candy storage, considering that the decrease in anthocyanin content occurred after 180 days. Bioactive compounds are sensitive to heat, and their rate of degradation varies with the severity of the process (Shinwari \& Rao, 2018). Among the anthocyanins present in pitanga fruit is delfinidine-3-glycoside, which is also highly influenced by heat (Einbond et al., 2004; Vergara et al., $2020 \mathrm{~b}$ ). The effects of processing and storage on the retention of bioactive compounds incorporated from different processed açaí pulps (frozen, spray-dried, and freeze-dried powder) in chewable candies without sucrose addition were evaluated by Silva et al. (2016). They reported that chewable candies containing lyophilized açaí pulp showed greater retention of phenolic compounds and anthocyanins immediately after production.

Conventional candies showed no significant difference $(\mathrm{p} \geq 0.05)$ in carotenoid content over the storage period (Figure 3). In general, there was a peak in carotenoid content after 60 days of storage. The increase in the level of this compound was probably due to the greater extractability of the analyte or the release of the food matrix after exposure to heat, making the carotenoid more available (Rodriguez-Amaya et al., 2008). After $1,60,120$, and 180 days of storage, there was no significant difference $(p \geq 0.05)$ in the carotenoid contents of the different
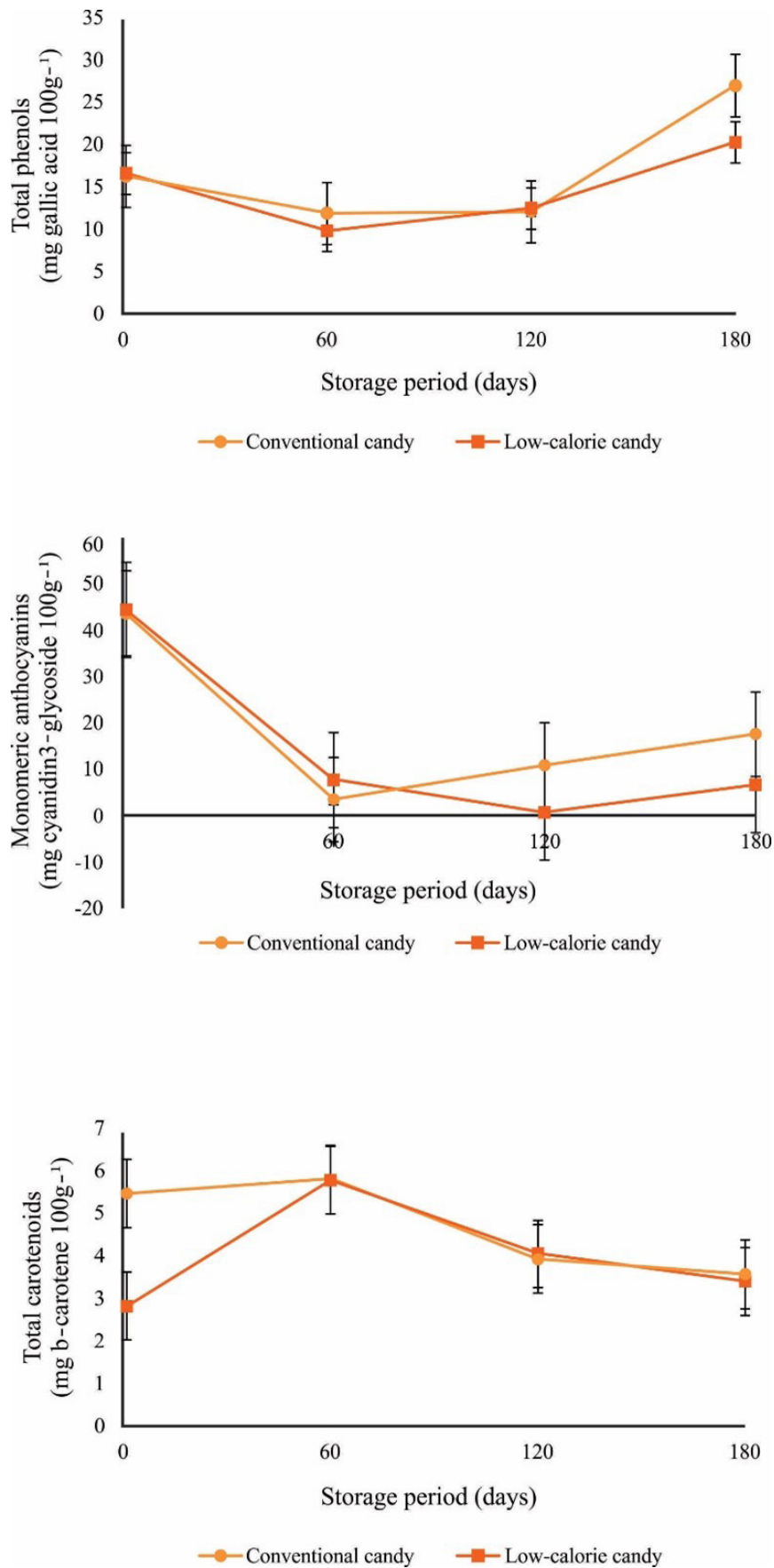

Figure 3. Phenolic compound, monomeric anthocyanin, and total carotenoid contents of conventional and low-calorie red pitanga chewable candies during 180 days of storage. The points in the lines represent de mean and the vertical bars indicate the $95 \%$ confidence interval among storage periods within each candy formulation.

candy formulations (Table 1). In a study with candies developed with different fruits from the Cerrado (Brazil), it was possible to observe good retention of total carotenoids after processing, especially Ananás (Ananas ananasoides), which obtained retention of $42.24 \%$. It demonstrates the feasibility of using fruit pulp to elaborate products without artificial coloring and potentially nutraceutical (Avelar et al., 2016). 


\subsection{Radical-scavenging activity}

The antioxidant activity against both the $\mathrm{ABTS}^{\circ}$ and $\mathrm{DPPH}^{\circ}$ radicals reached zero at the end of the storage period for conventional and low-calorie candies (Figure 4). At this point, the compounds may have been partially degraded or converted to other chemical species that do not act as antioxidants (Vergara et al., 2020b). At all the storage periods evaluated, there was no significant difference $(\mathrm{p} \geq 0.05)$ between the antioxidant activity of the conventional and low-calorie candies, determined using the $\mathrm{ABTS}^{\circ}$ and $\mathrm{DPPH}^{\circ}$ radical levels (Table 1). In a study with pectin and gelatin gummy confections incorporated with $25 \%(\mathrm{w} / \mathrm{w})$ of red pitaya fruit puree, the authors observed higher DPPH radical-scavenging activity on the $0^{\text {th }}$ day compared to the $56^{\text {th }}$ at $25^{\circ} \mathrm{C}$. The activity decreased along the storage period, similar to that observed in the pitanga candies. They attributed the decrease in DPPH inhibition to the decomposition of pigment compounds and their derivatives in the red pitaya fruit puree during the storage. The high radical-scavenging activity on the 0 th day was probably due to the higher degree of hydroxylation in the structure of the compounds (Hani et al., 2015). In the present study, the candies made with pitanga pulp also showed higher anthocyanin content at the beginning of the storage period, sharply decreasing at 60 days and remaining with values lower than the initial ones until the end of storage.

\subsection{Microbiological quality assessment}

The candies showed a TCC lower than the maximum allowed by legislation, as well as the absence of Salmonella spp.; therefore, they were considered suitable for consumption (Brasil, 2001) (Table 2). Miranda et al. (2020), when evaluating the microbiological quality of probiotic gelatin candy enriched with fruits native to Brazil's Atlantic Forest, obtained results that complied with RDC No. 12/2001 (ANVISA), which recommends a maximum limit of $10 \mathrm{MPN} / \mathrm{g}$ for coliforms at $45^{\circ} \mathrm{C}$ (thermotolerant), and absence of Salmonella spp. in $25 \mathrm{~g}$ of the product, indicating that the candies conformed to the current legal standards, guaranteeing the quality of the formulation and raw materials used.

These results demonstrate that the fruits used were healthy and properly sanitized. They also show that the processing of the candies was adequate, with no contamination of the product by thermotolerant coliforms and Salmonella spp. At the end of the storage period, both formulation presented similar behavior in terms of stability, being suitable for consumption for a period of up to 120 days of storage. Heat processing and the use of citric acid as an acidulant also contributed to the safety of the product. Rivero et al. (2021) added propolis extract to lowcalorie gelatin candies made with orange and raspberry juice, as a source of polyphenols and natural preservatives. They observed microbiological stability during 90 days at $25^{\circ} \mathrm{C}$.

\subsection{Sensory evaluation}

The ages of the participants involved in sensory evaluation ranged from 5 to 10 years. The group that evaluated the conventional candy comprised 50\% female and 50\% male participants. The evaluation group of the low-calorie candy comprised $54.28 \%$ female and $45.71 \%$ male participants.

The results obtained based on the hedonic scale totaled $91.43 \%$ and $95.71 \%$ of expressions corresponding to the terms "good," "very good," and "great" for the conventional and lowcalorie candies, respectively, indicating that both formulations
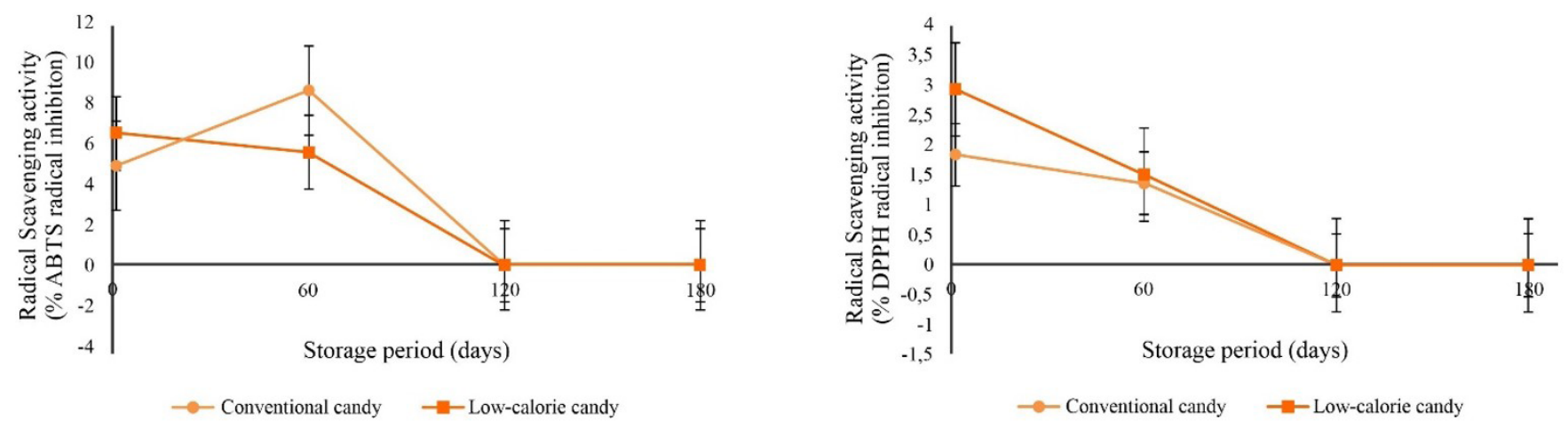

Figure 4. Antioxidant activity of conventional and low-calorie red pitanga chewable candies against $\mathrm{ABTS}^{\circ}$ and $\mathrm{DPPH}^{\circ}$ radicals during 180 days of storage. The points in the lines represent de mean and the vertical bars indicate the $95 \%$ confidence interval among storage periods within each candy formulation.

Table 2. Thermotolerant coliforms count (TCC) and Salmonella spp. analysis of conventional and low-calorie red pitanga candies (Eugenia uniflora L.).

\begin{tabular}{cccc}
\hline & Conventional candy & Low-calorie candy & Legislation parameters \\
\hline Thermotolerant coliforms at $45^{\circ} \mathrm{C}\left(\mathrm{MPN} \mathrm{g}^{-1}\right)^{*}$ & $<3.0$ & 3.6 & 10 \\
Salmonella spp. & Absent & Absent & Absent in $25 \mathrm{~g}$ \\
\hline
\end{tabular}

${ }^{\star} \mathrm{MPN} \mathrm{g}^{-1}$ : most probable number per gram; RDC Resolution No. 12/2001 (Brasil, 2001). 


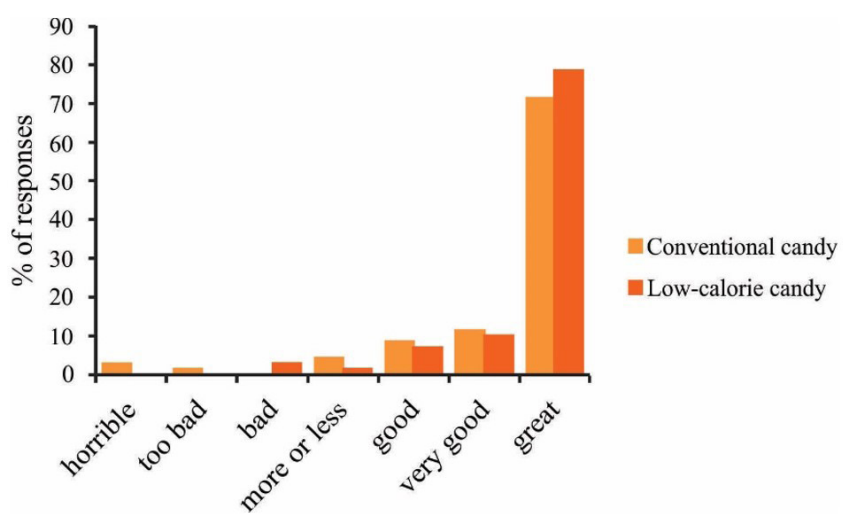

Figure 5. Sensory analysis histogram of conventional and low-calorie red pitanga chewable candies in relation to the frequency of hedonic values attributed to the global impression on children $(n=70)$.

were well accepted (Figure 5). The AI values of $90.61 \%$ and $94.28 \%$ for the conventional and low-calorie candies, respectively, corroborated this result. This behavior is remarkable, considering that candies are widely consumed by children. Silva et al. (2016) evaluated the effect of adding dried açai pulp by spray-drying on the sensory attributes of chewable candies with and without sucrose and found that the candy without sucrose achieved better results (good purchase intention score) than that containing sucrose. A recent study investigated the substitution of sucrose for soluble wheat fiber in low calorie gummy candies, and the sensory results showed acceptable sensory properties. They also tested mannitol as bulking and sweetener agent, however, negative changes were encountered in quality parameters (Gok et al., 2020). It is possible to observe that several sugar substitutes can be used for the preparation of low-calorie candies, depending on the processing and the constituents of the formulation, as they will influence the physicochemical and sensory characteristics of the product.

\section{Conclusions}

This study demonstrated that the incorporation of red pitanga pulp in chewable candies conferred positive physicochemical characteristics onto these products, mainly due to the partial retention of bioactive compounds after processing and storage. The development of red pitanga chewable candies is a viable alternative to aid small native fruit consumption, in addition to being an option for incorporating bioactive compounds in the product and a substitute for artificial food coloring.

\section{References}

Associação Brasileira da Indústria de Chocolates Amendoim e Balas ABICAB. (2019). Mercado de balas no Brasil. Retrieved from www. abicab.org.br/paginas/balas/mercado-2018-1.

Associação Brasileira de Normas Técnicas - ABNT. (1993). NBR 12806: Análise sensorial de alimentos e bebidas. Rio de Janeiro: ABNT.

Association of Official Analytical Chemists - AOAC. (2005). Official methods of analysis of the Association of Official Analytical Chemists (18th ed.). Gaithersburg: AOAC International.
Avelar, M. H. M., Rodrigues, C. G., Arruda, A. C., Silva, E. C., \& Carlos, L. A. (2016). Desenvolvimento de balas de goma elaboradas com frutas do Cerrado. Magistra, 28(1), 21-28.

Brand-Williams, W., Cuvelier, M. E., \& Berset, C. (1995). Use of a free radical method to evaluate antioxidant activity. Food Science and Technology, 28(1), 25-30.

Brasil, Ministério da Saúde. (2001). Resolução RDC nº 12, de 02 de janeiro de 2001. Regulamento técnico sobre padrões microbiológicos para alimentos. Diário Oficial da União.

Centro de Tecnologia de Embalagem - CETEA. (1993). Embalagens para chocolates, balas e derivados. Campinas: CETEA/ITAL.

Cruxen, C. E. S., Hoffmann, J. F., Zandoná, G. P., Fiorentini, A. M., Rombaldi, C. V., \& Chaves, F. C. (2017). Probiotic butia (Butia odorata) ice cream: development, characterization, stability of bioactive compounds, and viability of Bifidobacterium lactis during storage. Lebensmittel-Wissenschaft + Technologie, 75, 379-385. http:// dx.doi.org/10.1016/j.lwt.2016.09.011.

Einbond, L. S., Reynertson, K. A., Luo, X.-D., Basile, M. J., \& Kennelly, E. J. (2004). Anthocyanin antioxidants from edible fruits. Food Chemistry, 84(1), 23-28. http://dx.doi.org/10.1016/S0308-8146(03)00162-6.

Fadini, A. L., Facchini, F., Queiroz, M. B., Anjos, V. D. A., \& Yotsuyanagi, K. (2003). Influência de diferentes ingredientes na textura de balas moles produzidas com e sem goma gelana. Boletim CEPPA, 21(1), 131-140. http://dx.doi.org/10.5380/cep.v21i1.1154.

Franzon, R. C. (2013). Pitanga: fruta de sabor agradável e de usos diversos. Embrapa Clima Temperado. Retrieved from http://www.infoteca. cnptia.embrapa.br/bitstream/doc/976014/1/PitangaFranzon.pdf.

Gok, S., Toker, O. S., Palabiyik, I., \& Konar, N. (2020). Usage possibility of mannitol and soluble wheat fiber in low calorie gummy candies. Food Science and Technology, 128, 109531.

Haminiuk, C. W. I., Maciel, G. M., Plata-Oviedo, M. S. V., \& Peralta, R. M. (2012). Phenolic compounds in fruits - an overview. International Journal of Food Science \& Technology, 47(10), 2023-2044. http:// dx.doi.org/10.1111/j.1365-2621.2012.03067.x.

Hani, N. M., Romli, S. R., \& Ahmad, M. (2015). Influences of red pitaya fruit puree and gelling agents on the physico-mechanical properties and quality changes of gummy confections. International Journal of Food Science \& Technology, 50(2), 331-339. http://dx.doi. org/10.1111/ijfs.12638.

Lees, D. H., \& Francis, F. J. (1972). Standardization of pigment analyses in cranberries. Horticultural Science, 7, 83-84.

Lira, J. S., Bezerra, J. E. F., Lederman, I. E., \& Silva, J. F. (2007). Pitangueira (1. ed.). Recife: Empresa Pernambucana de Pesquisa Agropecuária-IPA.

Mahawar, M. K., Jalgaonkar, K., Bibwe, B., Kulkarni, T., Bhushan, B., \& Meena, V. S. (2018). Optimization of mixed aonla-guava fruit bar using response surface methodology. Nutrition \& Food Science, 48(4), 621-630. http://dx.doi.org/10.1108/NFS-09-2017-0189.

Miranda, J. S., Costa, B. V., Oliveira, I. V., Lima, D. C. N., Martins, E. M. F., Leite Júnior, B. R. C., Benevenuto, W. C. A. N., Queiroz, I. C., Silva, R. R., \& Martins, M. L. (2020). Probiotic jelly candies enriched with native Atlantic Forest fruits and Bacillus coagulans GBI-30 6086. Lebensmittel-Wissenschaft + Technologie, 126, 109275. http://dx.doi.org/10.1016/j.lwt.2020.109275.

Mongia, G. (2014). Fruit ingredients in confectionery applications. The Manufacturing Confectioner, 94, 73-82.

Moura, G. C., Fetter, M. R., Vizzotto, M., \& Antunes, L. E. C. (2011). Compostos bioativos e atividade antioxidante de pitangas em função de diferentes estádios de maturação e espaçamentos de plantio. Pelotas: 
Embrapa Clima Temperado. Retrieved from http://www.infoteca. cnptia.embrapa.br/handle/doc/926693.

Queiroz, M. I., \& Treptow, R. (2006). Análise sensorial para avaliação da qualidade dos alimentos. Rio Grande: Editora da FURG.

Reissig, G. N., Vergara, L. P., Franzon, R. C., Rodrigues, R. S., \& Chim, J. F. (2016). Bioactive compounds in conventional and no added sugars red strawberry guava (Psidium cattleianum Sabine) jellies. Revista Brasileira de Fruticultura, 38(3), e-062. http://dx.doi. org/10.1590/0100-29452016062.

Rickman, J. C., Bruhn, C. M., \& Barrett, D. M. (2007). Nutritional comparison of fresh, frozen, and canned fruits and vegetables II. Vitamin A and carotenoids, vitamin E, minerals and fiber. Journal of the Science of Food and Agriculture, 87(7), 1185-1196. http:// dx.doi.org/10.1002/jsfa.2824.

Rivero, R., Archaina, D., Sosa, N., \& Schebor, C. (2021). Development and characterization of two gelatin candies with alternative sweeteners and fruit bioactive compounds. LWT-Food Science and Technology, $141,110894$.

Rodriguez-Amaya, D. B., Kimura, M., \& Amaya-Farfan, J. (2008). Fontes brasileiras de carotenoides: tabela brasileira de composição de carotenoides em alimentos. Brasília: MMA/SBF. Retrieved from http://www.mma.gov.br/estruturas/sbf_agrobio/_publicacao/89_ publicacao09032009113306.pdf.

Rodriguez-Saona, L. E., \& Wrolstad, R. E. (2001). Extraction, isolation, and purification of anthocyanins. In: R. E. Wrolstad (Ed.), Current protocols in food analytical chemistry. New York: John Wiley \& Sons.

Rufino, M. S. M., Alves, R. E., Brito, E. S., Morais, S. M., Sampaio, G. C., Pérez-Jiménez, J., \& Saura-Calixto, F. D. (2007). Metodologia científica: determinação da atividade antioxidante total em frutas pela captura do radical livre ABTS. Fortaleza: Embrapa Agroindústria Tropical.

Shinwari, K. J., \& Rao, P. S. (2018). Stability of bioactive compounds in fruit jam and jelly during processing and storage: A review.
Trends in Food Science \& Technology, 75, 181-193. http://dx.doi. org/10.1016/j.tifs.2018.02.002.

Silva, L. B., Annetta, F. E., Alves, A. B., Queiroz, M. B., Fadini, A. L., Silva, M. G., \& Efraim, P. (2016). Effect of differently processed açaí (Euterpe oleracea Mart.) on the retention of phenolics and anthocyanins in chewy candies. International Journal of Food Science \& Technology, 51(12), 2603-2612. http://dx.doi.org/10.1111/ijfs.13245.

Silva, N., Junqueira, V. C. A., Silveira, N. F. A., Taniwaki, M. H., Santos, R. F. S., \& Gomes, R. A. R. (2007). Manual de métodos de análise microbiológica de alimentos. São Paulo: Ed. Varela.

Singleton, V. L., \& Rossi, J. A. J. R. (1965). Colorimetry of total phenolic with phosphomolybdic-phosphotungstic acid reagents. American Journal of Enology and Viticulture, 16(3), 144-158.

Vergara, L. P., Oliveira, R. M., Franzon, R. C, Chim, J. F., Borges, C. D., \& Zambiazi, R. C. (2020a). Efeito da retenção de compostos bioativos em balas mastigáveis formuladas com polpa blend. Brazilian Journal of Development, 6(11), 90148-90159.

Vergara, L. P., Reissig, G. N., Franzon, R. C., Carvalho, I. R., Zambiazi, R. C., Rodrigues, R. S., \& Chim, J. F. (2020b). Stability of bioactive compounds in conventional and low-calorie sweet chewable candies prepared with red and yellow strawberry guava pulps. International Food Research Journal, 27(4), 625-634.

Vinholes, J., Lemos, G., Barbieri, R. L., Franzon, R. C., \& Vizzotto, M. (2017). In vitro assessment of the antihyperglycemic and antioxidant properties of araçá, butiá and pitanga. Food Bioscience, 19, 92-100. http://dx.doi.org/10.1016/j.fbio.2017.06.005.

Vissoto, Z. F., \& Luccas, V. (1999). Tecnologia de fabricação de balas. Campinas: ITAL.

Zhang, X., Chen, F., \& Wang, M. (2013). Impacts of selected dietary polyphenols on caramelization in model systems. Food Chemistry, 141(4), 3451-3458. http://dx.doi.org/10.1016/j.foodchem.2013.06.053. PMid:23993506. 